\title{
Effects of skim milk and isotonic drink consumption before exercise on fluid homeostasis and time-trial performance in cyclists: a randomized cross-over study
}

Danniela García-Berger ${ }^{1}$, Karen Mackay², Matias Monsalves-Alvarez³ , Carlos Jorquera', Rodrigo Ramirez-Campillo ${ }^{4}$, Hermann Zbinden-Foncea ${ }^{5}$ and Mauricio Castro-Sepulveda ${ }^{5^{*}}$

\begin{abstract}
Background: Hydration status affects endurance performance. Pre-exercise hydration recommendations target the consumption of high carbohydrate and sodium beverages. Milk, due to its carbohydrate and sodium content, may be considered an effective pre-exercise hydration beverage.

Purpose: In a randomized cross-over trial, we compared the effects of an isotonic sport drink (SPD) with skim milk (SM) consumption before a race, on fluid homeostasis and time-trial performance in road cyclists.

Methods: Male road cyclists ( $n=9$; age, $26.8 \pm 4.78$ years) with $10.8 \pm 8.56$ years of experience in national competitions, consumed either SPD or SM in doses of $350 \mathrm{~mL}$ at $3 \mathrm{~h}$ and $350 \mathrm{~mL}$ at $1.5 \mathrm{~h}$ before a $18.6 \mathrm{~km}$ time-trial race. Measurements of body mass, urine specific gravity (USG), urine color and time-trial were compared between drinks (group; g) before and after the race (time; $\mathrm{t}$ ).

Results: The two-way ANOVA showed no differences between SPD and SM in body mass (t, $p<0.0001 ; g, p=0.89$; $\mathrm{t} \times \mathrm{g}, p=0.54)$, USG (t, $p=0.01 ; \mathrm{g}, p=0.63 ; \mathrm{t} \times \mathrm{g}, p=0.29$ ) and urine color (,$p=0.01 ; \mathrm{g}, p=0.54 ; \mathrm{t} \times \mathrm{g}, p=0.28)$ before or after race. Furthermore, no differences on water consumption during the race $(p=0.55)$ or time-trial performance ( $p=0.84$ ) were observed between trials.

Conclusion: Current results may help athletes with different beverages preferences to increase their options of hydration strategies.
\end{abstract}

Keywords: Hydration, Sport drink, Milk, Cyclists, Endurance sport, Urine specific gravity

\footnotetext{
* Correspondence: mcastro@uft.cl

${ }^{5}$ Exercise Science Laboratory, School of Kinesiology, Faculty of Medicine,

Universidad Finis Terrae, Av. Pedro de Valdivia \# 1509, Providencia, Santiago,

Chile

Full list of author information is available at the end of the article
}

(c) The Author(s). 2020 Open Access This article is licensed under a Creative Commons Attribution 4.0 International License, which permits use, sharing, adaptation, distribution and reproduction in any medium or format, as long as you give appropriate credit to the original author(s) and the source, provide a link to the Creative Commons licence, and indicate if changes were made. The images or other third party material in this article are included in the article's Creative Commons licence, unless indicated otherwise in a credit line to the material. If material is not included in the article's Creative Commons licence and your intended use is not permitted by statutory regulation or exceeds the permitted use, you will need to obtain permission directly from the copyright holder. To view a copy of this licence, visit http://creativecommons.org/licenses/by/4.0/ The Creative Commons Public Domain Dedication waiver (http://creativecommons.org/publicdomain/zero/1.0/) applies to the data made available in this article, unless otherwise stated in a credit line to the data. 


\section{Introduction}

The position statement of the American College of Sports Medicine on exercise and fluid replacement stated that a hypohydration greater than $2 \%$ of body mass impairs endurance exercise performance $[1,2]$. Specifically in cyclists, hypohydration has shown to decrease time-trial performance independent of thirst or when there is unknown hydration state [3-6]. Therefore, hydration strategies during and after competition are fundamental to maintain exercise capacity and will contribute to optimal performance during competition, especially in long lasting endurance events [7]. Nevertheless, research involving these strategies are scarce. The interest of pre-exercise hydration recommendations have shown that the consumption of beverages with high amounts of sodium and different types of carbohydrates can reduce fluid loss and improve fluid balance during exercise $[1,8]$. Previous research involving pre-exercise consumption of chicken soup [9] and non-alcoholic beer [10] have shown improved fluid balance during exercise. However, none of these studies considered performance.

The use of chocolate skim milk (CSM) has become an alternative to other commercially distributed isotonic sport drinks (SPD). In a literature review article, Pritchett et al. (2012) concluded that consuming CSM immediately after exercise and at $2 \mathrm{~h}$ post-exercise, attenuated indices of muscle damage and favored optimal exercise recovery [11]. Moreover, CSM, when compared to other SPD, provided similar or superior effects on ratings of perceived exertion, serum lactate, and serum creatine kinase after exercise [12]. These results suggest that post-exercise hydration drinks could also be effective when used as preexercise hydration beverages [1]. So, the use of CSM, could be considered a potential prior to exercise sport drink. However, CSM has almost twice as many calories as any other SPD, which could lead to gastrointestinal discomfort. Liquid gastric emptying depends on the total caloric content of beverages [13]. Thus, the ingestion of CSM prior to exercise could delay gastric emptying and cause discomfort in athletes. However, the use of non-chocolate skim milk (SM) may be an alternative to CSM. SM has lower calories due to lower carbohydrate content but yet similar nutritional content (other than carbohydrate) compared to CSM. Moreover, it also has similar amount of calories when compared to traditional SPD. Therefore, the aim of this study was to compare the use of a isotonic sport drink (SPD) and skim milk (SM) as a pre-race hydration beverage on fluid homeostasis and time-trial performance in road cyclists.

\section{Materials and methods Participants}

Nine male road cyclists (age, $26.8 \pm 4.78$ years; body mass, $71.9 \pm 5.33 \mathrm{~kg}$; height, $175.5 \pm 4.07 \mathrm{~cm}$ ), volunteered for the study. The participants had similar training level (>three training sessions per week) and $10.8 \pm 8.56$ years of experience in national competitions. All of the cyclists were current competitors (i.e., recently competed or training for an upcoming competition) at the time of testing. Also, all athletes were regular consumers of SM and presented no lactose intolerance. They were carefully informed about all the experimental procedures and risks/ benefits associated with their participation in the study. Participants were given a written informed consent and signed the document before any of the experimental testing was performed. This study was conducted in accordance with the Declaration of Helsinki and was approved by the ethics committee of University ** blind for review purposes $^{* * *}$ (to be completed after peer review).

\section{Experimental design}

Each cyclist completed two pre-exercise hydration protocols (5-days of separation between) in a randomized crossover design, before an $18.6 \mathrm{~km}$ time-trial race. The timetrial was conducted on a first category mountain pass which the cyclists were familiar with, and frequently used in cycling competitions. The mountain is located at the Metropolitan Region of Chile (Farellones), with an altitude of $\sim 2430 \mathrm{~m}$ over sea level and an average gradient of $\sim 5 \%$. The time-trial was supervised by the main researcher on an individual basis. To increase the ecological validity, no hydration recommendations were made before the trials. Prior to each trial the athletes ingested two doses of 350 $\mathrm{mL}\left(700 \mathrm{~mL}\right.$ total), of either SPD (Gatorade $\left.{ }^{\bullet}, \mathrm{USA}\right)$ or SM (Colun ${ }^{\circ}$, Chile) (drinks characteristics in Table 1). The doses were given $180 \mathrm{~min}$ and $90 \mathrm{~min}$ before each race (protocol time-chart in Fig. 1).

\section{Measurements}

Measurements of body mass (SECA, Germany), USG (refractometer; Robinair, USA), and urine color (scale 1 to 8) were assessed after the consumption of $700 \mathrm{~mL}$ of the drinks (Time 1) and after the completion of the race (Time 2) (Fig. 1). In addition, baseline USG was also evaluated before drink consumption. For urine collection, a disposable, clean, dry and transparent container was used. Time-trial performance was assessed on each

Table 1 Nutritional characteristics of drinks per $350 \mathrm{~mL}$

\begin{tabular}{lll}
\hline Characteristics & Skim milk (SM) & Isotonic sport drink (SPD) \\
\hline Energy (Kcal) & 112 & 84 \\
Protein (g) & 11.5 & 0 \\
Fat (g) & 0.1 & 0 \\
Carbohydrates (g) & 16.4 & 21 \\
Sodium (mg) & 112 & 185 \\
Potassium (mg) & 384 & 32 \\
\hline
\end{tabular}




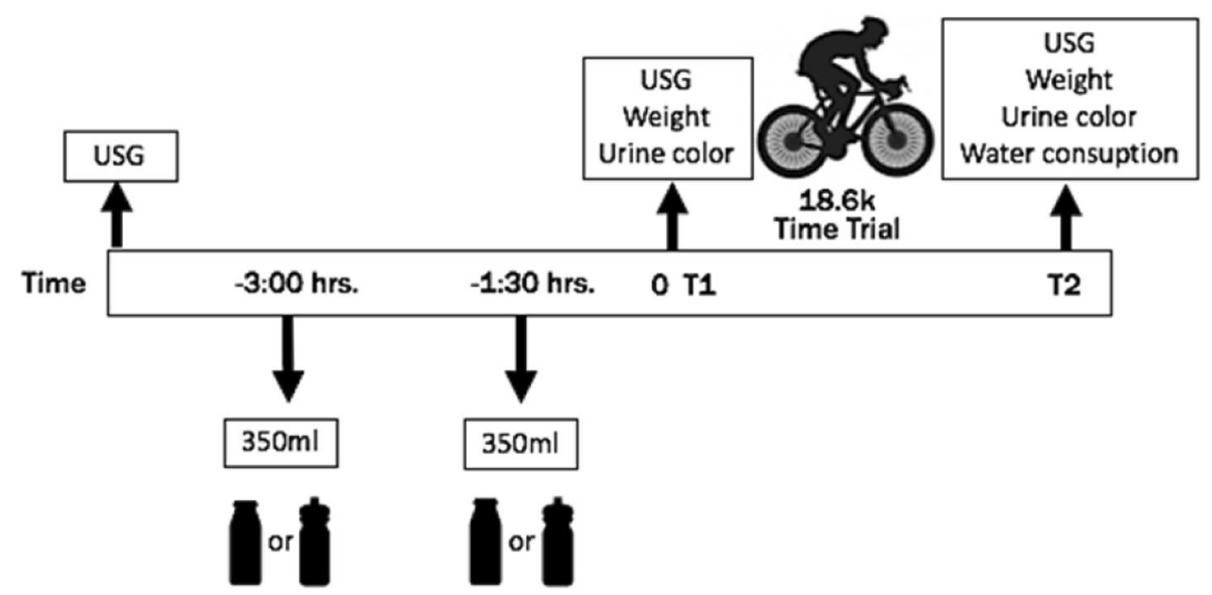

Fig. 1 Time chart of the study protocol. USG: Urine specific gravity. T: Time

$18.6 \mathrm{~km}$ race using a chronometer (Casio, Japan) with precision at normal temperature $+/-99.9 \%$.

To assess liquid intake during the race, $500 \mathrm{~mL}$ water bottles (Vital, Chile) were given to each cyclist to be consumed freely during the exercise (ad libitum) at the beginning of the race. Wind, speed, temperature and humidity, was measured using the AccuWeather application. Temperature and humidity were similar (statistical analysis not showed) between SPD $\left(24^{\circ} \mathrm{C}\right.$ and $46 \%$ of humidity) and SM $\left(21^{\circ} \mathrm{C}\right.$ and $48 \%$ of humidity).

\section{Statistical analysis}

Data normality was evaluated with the Shapiro-Wilk test, showing that data was normally distributed. The statistical analysis was performed with GraphPad Prism 6.0 program (Graphpad Software, USA). A paired $t$-test was used to compare water consumption during time-trials and the time needed to complete them. A two-way analysis of variance (2-way ANOVA) was applied to compare body mass, urine color and urine specific gravity before and after race (time) between trials (group) and their interaction $(\mathrm{t} \times \mathrm{g})$. All data are reported as mean \pm standard deviation. $p<0.05$ was considered statistically significant.

\section{Results}

Hydration status and fluid homeostasis

Group baseline USG (before the consumption of drinks) was $1.018 \pm 0.006$. According to Casa et al. (2000) [7], $11.7 \%$ of cyclist were euhydrated (USG < 1.010), 41.2\% mildly dehydrated (USG $=1.010-1.020$ ), $41.1 \%$ significantly dehydrated (USG $=1.021-1.030$ ), and $5.8 \%$ seriously dehydrated (USG > 1.030). Urine color and USG, both hydration status markers, increased after the race ( $\mathrm{t}, p=0.04 ; \mathrm{t}, p=0.01$; respectively). However, no differences were found between trials $(\mathrm{g}, p=0.63$; $\mathrm{g}, p=0.54$; respectively), nor in time $\mathrm{x}$ trials interaction $(\mathrm{t} \times \mathrm{g}, p=$ 0.29 ; $\mathrm{t} \times \mathrm{g}, p=0.28$; respectively) (see Fig. $2 \mathrm{~b}, \mathrm{c}$ ). Regarding body mass, both groups showed a reduction of $2.1 \pm$ $0.48 \%(\mathrm{t}, p<0.0001)$ after the race. However, no differences were found between trials $(\mathrm{g}, p=0.89$ ), nor in the time $\mathrm{x}$ trials interaction $(\mathrm{t} \times \mathrm{g}, p=0.54)$ (see Fig. 2a).

\section{Water consumption and time-trial performance}

No differences were observed on water consumption during the race and between trials $(\mathrm{SM}, 340 \pm 190 \mathrm{~mL}$; SPD, $288 \pm 196$; $p=0.55$, see Fig. 3a). Finally, no differences were observed in the $18.6 \mathrm{~km}$ time-trial between

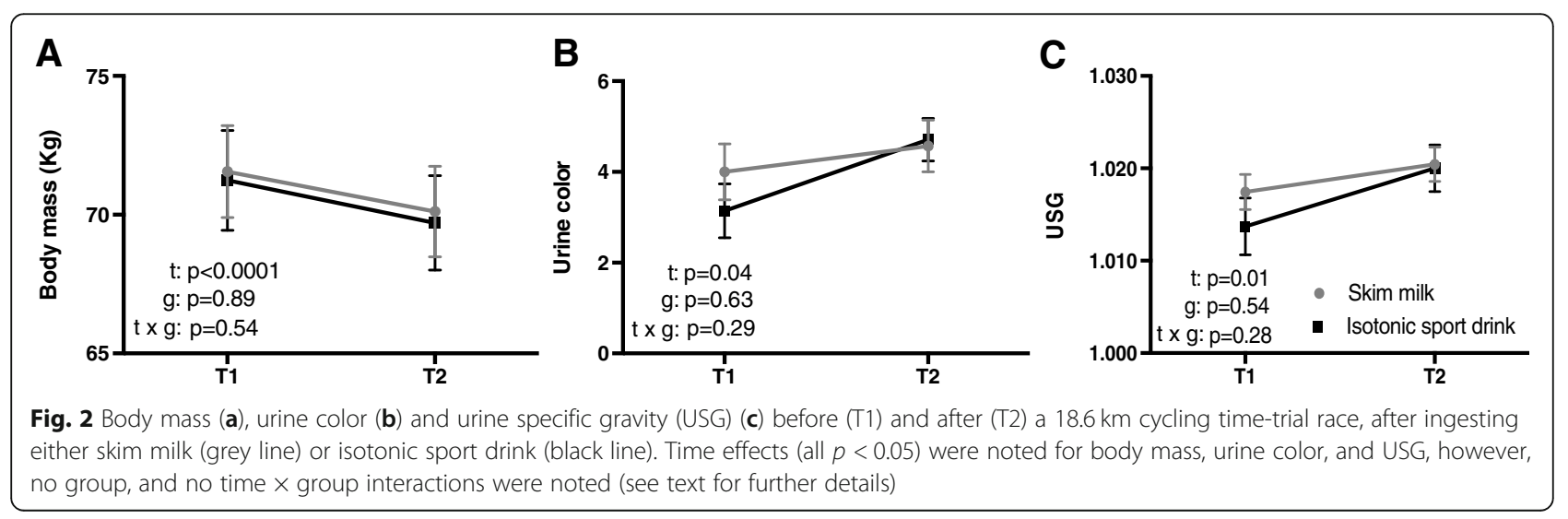



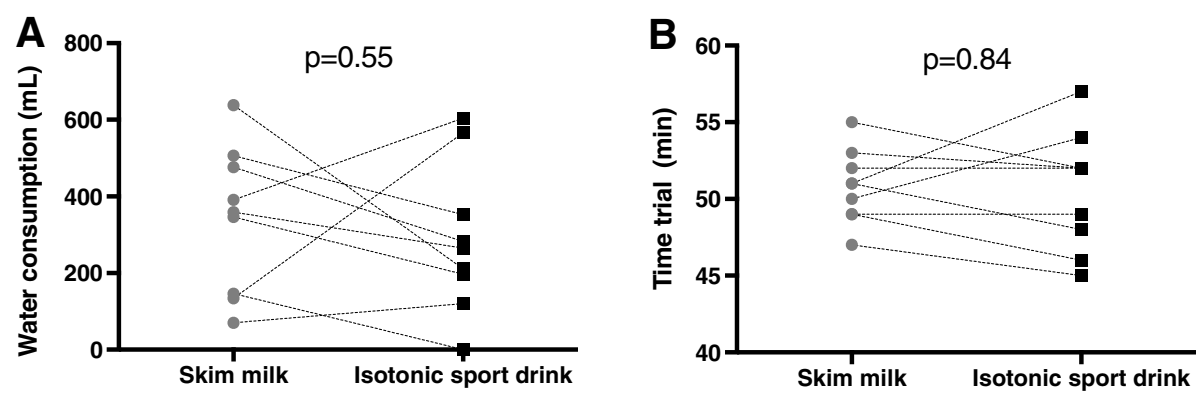

Fig. 3 Comparison of water consumption during - and the time needed to complete - a $18.6 \mathrm{~km}$ cycling time-trial race, after ingesting either skim milk or isotonic sport drink

beverages (SM, $50.6 \pm 3.9 \mathrm{~min}$; SPD, $50.8 \pm 2.39 \mathrm{~min} ; p=$ 0.84, see Fig. 3b).

\section{Discussion}

The aim of this study was to compare the use of an isotonic sport drink (SPD) and skim milk (SM) as a pre-race hydration beverage on fluid homeostasis and time-trial performance in road cyclists. We observed that SM had similar effects than SPD on fluid homeostasis and performance. Therefore, SM and SPD can be considered as alternatives to hydration drinks prior to a race in road cyclists.

Our results show that $88.2 \%$ of the cyclists recruited were dehydrated (USG > 1.010) prior to time-trials. Similar results regarding hydration status on athletes have been reported elsewhere. In a study performed by CastroSepúlveda et al. (2015) professional soccer players began training sessions with an average USG of $1.026 \pm 0.005$ (98\% dehydration prevalence) [14]. Furthermore, DíazCastro et al. (2018) observed basketball players with an average USG of $1.021 \pm 0.006$ (98\% dehydration prevalence) [15]. Thus, our results of poor hydration prior to competition are in accordance with the literature. It has been suggested that the lack of nutritional knowledge by athletes may be the main cause of a poor hydration status [16-19] prior to competition. Moreover, a recent finding suggests that mild pre-match dehydration (USG $=1.010-$ 1.020) increases the physiological stress during exercise [20]. Therefore, given the high prevalence of pre-exercise dehydration among athletes, pre-hydration strategies and nutritional education among athletes becomes essential.

The literature recommends different hydration protocols prior to exercise $[7,21]$. In this study, a total volume intake of $700 \mathrm{ml}$ was provided, divided into two doses of $350 \mathrm{ml}$, at 3 and $1.5 \mathrm{~h}$ prior to the time-trial. This volume was well accepted by the athletes, since no participant declared gastrointestinal discomfort. The literature explains, that most of the gastrointestinal discomfort which occurs during exercise is due to a reduction in gastric emptying speed, malabsorption of water and nutrients, delayed transit time or a reduction in flow splanchnic blood [22]. Most importantly, gastrointestinal discomfort during exercise has shown to impair performance in endurance athletes [22]. Therefore, the prevalence of gastrointestinal discomfort and symptoms during training and competition becomes relevant. It has been suggested that high caloric content in beverages affects gastric emptying. A study by Okabe et al. (2015) compared five types of beverages with different caloric contents (including milk, orange juice and water) and observed no differences in the time of liquid gastric emptying. Therefore, liquid gastric emptying can depend of more nutrients rather than only the total caloric content of the drinks [13]. Our participants reported no gastrointestinal discomfort with the use of SM or SPD. These results support the use of SM as a pre hydration drink, free of any gastrointestinal risks or symptoms.

In the present study, no time differences were found between SM and SPD in the completion of an $18.6 \mathrm{~km} \mathrm{cyc-}$ ling time-trial. Similar results where showed by Pritchett et al. (2009), where chocolate skim milk and SPD were ingested prior to a time to exhaustion trial at $85 \%$ of participant's maximal oxygen uptake [23]. However, there could be an additional benefit to the use of SM (whether chocolate or not) relative to SPD. The use of SM could contribute in reducing skeletal muscle damage caused by exercise, presumably due to the amino acid content in SM [11]. Further research in this topic is warranted.

In conclusion, our results show that the use of SM as a pre-hydration beverage observed no differences on fluid homeostasis or performance when compared to SPD in trained cyclists. Also, the use of SM presented good gastrointestinal tolerance within the athletes. Therefore, the use of SM could be considered another effective hydration strategy for athletes with different beverages preferences.

\section{Abbreviations \\ CSM: Chocolate skim milk; SM: Skim milk; SPD: Isotonic sport drink; USG: Urine specific gravity}

\section{Acknowledgements}

The authors would like to acknowledge the commitment and effort of all the athletes who participated in this study "Club La Cumbre". 


\section{Authors' contributions}

DG and $M C$ conceived and designed the study. DG collected data. MC, DG, $M M, K M$ and $H Z$ analyzed data and reported results. MC, MM, KM, CJ and RR constructed the first manuscript. All authors edited the manuscript and approved the final version of manuscript.

\section{Funding}

There was no funding for this study.

\section{Availability of data and materials}

The datasets used and/or analyzed during the current study are available from the corresponding author on reasonable request.

\section{Ethics approval and consent to participate}

The methods and procedures of the present study were approved by the University Mayor of Santiago, Chile and were performed in accordance with the ethical standards from the 1964 Declaration of Helsinki. All participants provided approved written informed consent prior to study initiation.

\section{Consent for publication}

Not applicable.

\section{Competing interests}

The authors declare that they have no competing interests.

\section{Author details}

${ }^{1}$ Nutrition and Exercise laboratory, Faculty of Medicine, Universidad Mayor, Santiago, Chile. ${ }^{2}$ School of Exercise and Nutrition, Faculty of Health, Queensland University of Technology, Brisbane, Australia. ${ }^{3}$ Human Performance Laboratory, Motion Health \& Performance Center, Santiago, Chile. ${ }^{4}$ Laboratory of Human Performance. Quality of Life and Wellness Research Group. Department of Physical Activity Sciences, Universidad de Los Lagos, Osorno, Chile. ${ }^{5}$ Exercise Science Laboratory, School of Kinesiology, Faculty of Medicine, Universidad Finis Terrae, Av. Pedro de Valdivia \# 1509, Providencia, Santiago, Chile.

\section{Received: 7 November 2019 Accepted: 11 March 2020}

\section{Published online: 30 March 2020}

\section{References}

1. American College of Sports Medicine, Sawka MN, Burke LM, et al. American College of Sports Medicine position stand. Exercise and fluid replacement. Med Sci Sports Exerc. 2007;39(2):377-90.

2. Cheuvront SN, Carter R, Sawka MN. Fluid balance and endurance exercise performance. Curr Sports Med Rep. 2003;2(4):202-8.

3. Funnell MP, Mears SA, Bergin-Taylor K, James L. Blinded and unblinded hypohydration similarly impair cycling time trial performance in the heat in trained cyclists. J Appl Physiol Bethesda Md 1985. 2019;126(4):870-9.

4. Adams JD, Sekiguchi Y, Suh H-G, Seal AD, Sprong CA, Kirkland TW, et al. Dehydration impairs cycling performance, independently of thirst: a blinded study. Med Sci Sports Exerc. 2018;50(8):1697-703.

5. Bardis CN, Kavouras SA, Kosti L, Markousi M, Sidossis LS. Mild hypohydration decreases cycling performance in the heat. Med Sci Sports Exerc. 2013;45(9): $1782-9$.

6. Adams JD, Scott DM, Brand NA, Suh H-G, Seal AD, McDermott BP, et al. Mild hypohydration impairs cycle ergometry performance in the heat: a blinded study. Scand J Med Sci Sports. 2019;29(5):686-95.

7. Casa DJ, Armstrong LE, Hillman SK, Montain SJ, Reiff RV, Rich BS, et al. National athletic trainers' association position statement: fluid replacement for athletes. J Athl Train. 2000;35(2):212-24.

8. Savoie FA, Dion T, Asselin A, Goulet EDB. Sodium-induced hyperhydration decreases urine output and improves fluid balance compared with glyceroland water-induced hyperhydration. Appl Physiol Nutr Metab Physiol Appl Nutr Metab. 2015:40(1):51-8.

9. Johannsen NM, Sullivan ZM, Warnke NR, Smiley-Oyen AL, King DS, Sharp RL. Effect of preexercise soup ingestion on water intake and fluid balance during exercise in the heat. Int J Sport Nutr Exerc Metab. 2013;23(3):287-96.

10. Castro-Sepulveda M, Johannsen N, Astudillo S, Jorquera C, Álvarez C, Zbinden-Foncea $\mathrm{H}$, et al. Effects of Beer, Non-Alcoholic Beer and Water Consumption before Exercise on Fluid and Electrolyte Homeostasis in Athletes. Nutrients. 2016;8(6):345.
11. Pritchett K, Pritchett R. Chocolate milk: a post-exercise recovery beverage for endurance sports. Med Sport Sci. 2012;59:127-34.

12. Amiri M, Ghiasvand R, Kaviani M, Forbes SC, Salehi-Abargouei A. Chocolate milk for recovery from exercise: a systematic review and meta-analysis of controlled clinical trials. Eur J Clin Nutr. 2018;73(6):835-49.

13. Okabe T, Terashima H, Sakamoto A. Determinants of liquid gastric emptying: comparisons between milk and isocalorically adjusted clear fluids. Br J Anaesth. 2015;1 14(1):77-82.

14. Castro-Sepúlveda M, Astudillo S, Álvarez C, Zapata-Lamana R, ZbindenFoncea H, Ramírez-Campillo R, et al. Prevalence of dehydration before training in PROFESIONAL CHILEAN soccer players. Nutr Hosp. 2015;32(1): 308-11.

15. Díaz-Castro F, Astudillo S, Calleja-González J, Zbinden-Foncea H, RamirezCampillo R, Castro-Sepúlveda M. Change in marker of hydration correspond to decrement in lower body power following basketball match. Sci Sports. 2018;33(3):123-8.

16. Maughan RJ, Shirreffs SM. Development of individual hydration strategies for athletes. Int J Sport Nutr Exerc Metab. 2008;18(5):457-72.

17. Magee PJ, Gallagher AM, McCormack JM. High prevalence of dehydration and inadequate nutritional knowledge Among University and Club level athletes. Int J Sport Nutr Exerc Metab. 2016;27(2):158-68.

18. Judge LW, Kumley RF, Bellar DM, Pike KL, Pierson EE, Weidner T, et al. Hydration and fluid replacement knowledge, attitudes, barriers, and behaviors of NCAA division 1 American football players. J Strength Cond Res. 2016;30(11):2972-8.

19. Cleary MA, Hetzler RK, Wasson D, Wages JJ, Stickley C, Kimura IF. Hydration behaviors before and after an educational and prescribed hydration intervention in adolescent athletes. J Athl Train. 2012;47(3):273-81.

20. Castro-Sepulveda M, Ramirez-Campillo R, Abad-Colil F, Monje C, Peñailillo L, Cancino J, et al. Basal mild dehydration increase salivary cortisol after a friendly match in young elite soccer players. Front Physiol. 2018;9:1347.

21. Racinais S, Alonso JM, Coutts AJ, Flouris AD, Girard O, González-Alonso J, et al. Consensus recommendations on training and competing in the heat. Scand J Med Sci Sports. 2015;25(Suppl 1):6-19.

22. Schwartz AE, Vanagunas A, Kamel PL. Endoscopy to evaluate gastrointestinal bleeding in marathon runners. Ann Intern Med. 1990;113(8): 632-3.

23. Pritchett K, Bishop P, Pritchett R, Green M, Katica C. Acute effects of chocolate milk and a commercial recovery beverage on postexercise recovery indices and endurance cycling performance. Appl Physiol Nutr Metab Physiol Appl Nutr Metab. 2009;34(6):1017-22.

\section{Publisher's Note}

Springer Nature remains neutral with regard to jurisdictional claims in published maps and institutional affiliations.

Ready to submit your research? Choose BMC and benefit from:

- fast, convenient online submission

- thorough peer review by experienced researchers in your field

- rapid publication on acceptance

- support for research data, including large and complex data types

- gold Open Access which fosters wider collaboration and increased citations

- maximum visibility for your research: over $100 \mathrm{M}$ website views per year

At $\mathrm{BMC}$, research is always in progress.

Learn more biomedcentral.com/submissions 